\title{
Editorial
}

\section{Spatial Analysis for Landscape Changes}

\author{
Dario Gioia *(D) and Maria Danese *(1) \\ ISPC-CNR, C.da S. Loja, Tito Scalo, I-85050 Potenza, Italy \\ * Correspondence: dario.gioia@cnr.it (D.G.); maria.danese@cnr.it (M.D.)
}

Citation: Gioia, D.; Danese, M. Spatial Analysis for Landscape Changes. Appl. Sci. 2021, 11, 11924. https: / / doi.org/10.3390/ app112411924

Received: 6 December 2021

Accepted: 13 December 2021

Published: 15 December 2021

Publisher's Note: MDPI stays neutral with regard to jurisdictional claims in published maps and institutional affiliations.

Copyright: (c) 2021 by the authors. Licensee MDPI, Basel, Switzerland. This article is an open access article distributed under the terms and conditions of the Creative Commons Attribution (CC BY) license (https:// creativecommons.org/licenses/by/ $4.0 /)$.
Landscape is the backcloth over which environmental and anthropic events occur, and recent increasing trends of natural and anthropic processes, such as urbanization, land-use changes, and extreme climate events, have a strong impact on landscape modification. Indeed, day by day, landscape changes are becoming more drastic and faster and there is a growing need for the implementation of effective instruments, tools, and approaches to understand and manage them. A great improvement in the availability of high-resolution DEMs, GIS tools, and algorithms of automatic extraction of landform features and change detections has favored an increase in the analysis of landscape changes, which became an essential instrument for the quantitative evaluation of landscape changes in many research fields. This special issue collects six papers that highlight the usefulness of the quantitative analyses of satellite images and DEMs to solve multidisciplinary issues of landscape changes.

Rui et al. (2020) [1] introduce an analysis of the erosion factors controlling the evolution of a badland area of the National Geological Park of Qian, China. The influence of geological features, climate, groundwater, and soil on the geomorphological evolution of the study area has been discussed, in order to reconstruct a synoptic scheme of the main stages of morpho-evolution.

Yan et al. (2020) [2] describe an interesting approach of the semi-automatic extraction of subaqueous landforms using multibeam bathymetric data. The comparison of three different methods of landform classification (i.e., Wood's criteria, SOM, and geomorphons) highlights that the geomorphon method has the highest degree of accuracy for the automatic extraction of the bedforms of a delta system in China.

Gioia and Schiattarella (2020) [3] investigated the scenarios of sediment flux variation and topographic changes due to dam removal in a small catchment of the southern Italian Apennines. The application of a landscape evolution model (i.e., the Caesar Lisflood LEM) provides a detailed reconstruction of the abrupt geomorphological change induced by baselevel fall due to dam removal, which can be roughly summarized in the significant increase in the erosion ability of the main channels and a strong incision of the reservoir infill.

Martinez et al. (2021) [4] integrate satellite images and drone surveys to investigate the post-fire vegetation regeneration in a forest in Central-Eastern Spain. The spatial analysis of the topographic and image attributes and the application of vegetation indexes indicate that a similar analysis can be useful to evaluate the effect of post-fire vegetation restoration strategies.

Subudhi et al. (2021) [5] propose a new method of image segmentation of hyperspectral satellite images (i.e., the Superpixel-based SSA, SP-SSA), which can provide an improvement to the capturing of object-specific spatio-spectral information. The performance of the method is evaluated using an SVM classifier, suggesting that the proposed approach overperforms the standard SSA technique and various common spatio-spectral classification methods, in terms of classification accuracy.

Finally, Danese and Gioia (2021) present a review paper aimed at the bibliometric analysis of the research trends in the topic of the special issue, "Spatial Analysis for Landscape Changes". Such an analysis covers the last twenty years and investigates topics, 
trends, and methods that are connected to the research line through the statistical analysis of different metrics, such as the number of citations, co-authorship networks, and keyword occurrences. The results of the bibliometric analysis highlight that the topic has received increasing attention in the last years, and research methods are moving toward computerbased automation or the unsupervised detection of landscape patterns and changes.

Author Contributions: All authors contributed equally to the preparation of this manuscript. All authors have read and agreed to the published version of the manuscript.

Funding: This research received no external funding.

Acknowledgments: This publication was only possible with the invaluable contributions from the authors, reviewers, and the editorial team of Applied Sciences.

Conflicts of Interest: The authors declare no conflict of interest.

\section{References}

1. Rui, X.; Nie, L.; Xu, Y.; Du, C.; Kong, F; Zhang, T.; He, Y.; Wang, Y. Characterization of Evolution Stages, Groundwater and Soil Features of the Mud Forest Landscape at Qian-an (China). Appl. Sci. 2020, 10, 7427. [CrossRef]

2. Yan, G.; Cheng, H.; Teng, L.; Xu, W.; Jiang, Y.; Yang, G.; Zhou, Q. Analysis of the Use of Geomorphic Elements Mapping to Characterize Subaqueous Bedforms Using Multibeam Bathymetric Data in River System. Appl. Sci. 2020, 10, 7692. [CrossRef]

3. Gioia, D.; Schiattarella, M. Modeling Short-Term Landscape Modification and Sedimentary Budget Induced by Dam Removal: Insights from LEM Application. Appl. Sci. 2020, 10, 7697. [CrossRef]

4. Martinez, J.L.; Lucas-Borja, M.E.; Plaza-Alvarez, P.A.; Denisi, P.; Moreno, M.A.; Hernández, D.; González-Romero, J.; Zema, D.A. Comparison of Satellite and Drone-Based Images at Two Spatial Scales to Evaluate Vegetation Regeneration after Post-Fire Treatments in a Mediterranean Forest. Appl. Sci. 2021, 11, 5423. [CrossRef]

5. Subudhi, S.; Patro, R.; Biswal, P.K.; Dell'Acqua, F. Superpixel-Based Singular Spectrum Analysis for Effective Spatial-Spectral Feature Extraction. Appl. Sci. 2021, 11, 10876. [CrossRef] 